\title{
Influence of the Chemical Composition of Asphalt and the 3D Morphology of the Aggregate on Contact Surface Adhesion
}

\author{
Luoke Li ${ }^{1},{ }^{1}$ Meng Guo $\mathbb{D}^{2},{ }^{2}$ and Cong Zeng ${ }^{3}$ \\ ${ }^{1}$ Faculty of Civil Engineering and Mechanics, Kunming University of Science and Technology, Kunming 650500, China \\ ${ }^{2}$ The Key Laboratory of Urban Security and Disaster Engineering of Ministry of Education, Beijing University of Technology, \\ Beijing 100124, China \\ ${ }^{3}$ School of Civil Engineering and Architecture, Northeast Electric Power University, Jilin 132012, China \\ Correspondence should be addressed to Meng Guo; gm@bjut.edu.cn
}

Received 10 September 2020; Revised 17 November 2020; Accepted 8 December 2020; Published 4 January 2021

Academic Editor: Linglin Li

Copyright (c) 2021 Luoke Li et al. This is an open access article distributed under the Creative Commons Attribution License, which permits unrestricted use, distribution, and reproduction in any medium, provided the original work is properly cited.

\begin{abstract}
The influence of the chemical composition of asphalt, the aggregate lithology, and the morphological characteristics of the aggregate on the level of adhesion between the asphalt and the aggregate is investigated. A contactless three-dimensional (3D) white-light scanning technique is used to obtain point cloud data of the aggregate particles. Six independent feature parameters are used as evaluation indices to quantitatively describe the multilevel features of the 3D morphology of road aggregates. Methods for analyzing the feature parameters based on the point cloud data of the aggregate are presented. Subsequently, the process and evaluation standard of the adhesion test are improved to quantify the spalling degree of the asphalt film on the aggregate surface under boiling conditions. The influences of the chemical composition of the asphalt and the aggregate morphology on the level of adhesion between the asphalt and aggregate are analyzed, and the compatibility between aggregates with different lithologies and the asphalt is assessed. The results show that the shape factor $(S F)$ can be used to characterize the needle-flake shape of the particles, the ellipsoid index $(E)$ is suitable to determine the angularity of the aggregate particles, and the 3D joint roughness coefficient $\left(J R C^{3 \mathrm{D}}\right)$ describes the roughness of the particle surface. The type of adhesion between the aggregate and the asphalt includes chemical and physical adsorption; chemical bonding is relatively strong, and the physical orientation force and mechanical interlocking force are relatively weak. Alkaline limestone aggregates should be used with asphalt with a high aggregate content of colloid and asphaltenes. Basalt aggregate with weak alkalinity should be used with asphalt with a high colloid content, and the use of angular aggregates should be avoided. Acidic aggregates with compact shapes, few edges and corners, and rough surfaces should be used prudently.
\end{abstract}

\section{Introduction}

The adhesion performance between asphalt and aggregate at the contact surface reflects the ability of the asphalt membrane to resist damage and peeling and the bonding strength of the particles in the aggregate skeleton structure [1]. The types of adhesion between two materials at the contact interface include chemical and physical adsorption [2]. When polymer asphalt material consisting of multiple elements is in contact with the aggregate, chemical adsorption occurs at the contact surface, forming a chemical bond [3].
The viscous bituminous material can also penetrate into the microcrack pores of the rough surface of the aggregate; after solidification, a mechanical bonding force occurs at the contact surface [4]. Most research on the adhesion between asphalt and aggregate has focused on the chemical bonding between the asphalt and the aggregate surfactant or on measurements of the energy parameters of the material surface based on solid physics theory [5-10]. However, few studies have considered the effects of the particle shape, angularity, and roughness of the aggregate on the adhesion between the two materials. 
With the continuous development of measurement technology, several measurement methods have been applied to obtain three-dimensional (3D) morphological data of rock materials $[11,12]$. High-precision noncontact measurement technology based on the optical principle has several advantages for obtaining data on the surface topography of rock materials [13]. A 3D scanning device can quickly obtain point cloud data describing the $3 \mathrm{D}$ features of the aggregate particles. These data can be used for the physical reconstruction of the aggregate and the quantification of 3D morphological parameters [14].

Commonly used methods to test the adhesion of different asphalt and aggregate types include boiling, water immersion, agitated water purification, solvent elution, and ultrasonic peeling. Water boiling is the most widely used method because of its simple operation and equipment, and the peeling of the asphalt from the aggregate surface is easy to determine and intuitive. However, the evaluation index obtained from the test strip of the water-boiling method is not a quantitative index. The five-level grading index is relatively coarse, and it is not possible to distinguish differences in adhesion between different asphalt and aggregate types. Therefore, the test process and evaluation indicators of the boiling method have to be improved to obtain a quantitative measure of the difference in adhesion between different asphalt and aggregate types.

Therefore, in this study, we investigate the adhesion level between asphalt and aggregate from the perspective of physical adsorption and chemical adsorption. First, we determine the chemical composition of the test material and use a quantitative evaluation method to evaluate the $3 \mathrm{D}$ morphology of the aggregate surface. Second, we improve the test process of the water boiling method and propose an improved evaluation index. Third, we analyze the influences of the four asphalt components and the 3D morphology of the aggregate on the contact surface adhesion between the two materials. In addition, we investigate additional factors, analyze the degree of correlation between the level of adhesion between the two materials, and determine the compatibility between the asphalt and aggregates with different lithology.

\section{Materials and Methods}

2.1. Materials. Nine types of matrix asphalt and three types of coarse aggregates with different lithology were obtained from the Highway Science and Technology Research Institute of Yunnan Province.

The technical indices and chemical components of the raw materials were obtained using solvent precipitation and column adsorption methods according to the Chinese specification "test procedures for asphalt and asphalt mixtures for highway engineering" (JTG E20-2011) to investigate the influence of the chemical composition of asphalt on contact surface adhesion. The results are shown in Table 1.

The aggregate particle size range was $16 \mathrm{~mm}-19 \mathrm{~mm}$, and the aggregates were produced using jaw and counterattack crushers. The chemical composition of the three types of coarse aggregates was analyzed with X-ray fluorescence following the Chinese specification "methods for chemical analysis of silicate rocks" (GB/T 14506-2010); the results are shown in Table 2.

\subsection{Data Acquisition and Digital 3D Reconstruction of the} Aggregate Surface Topography. 3D point clouds of the surface of the aggregate particles were obtained using whitelight interferometry. The data were registered and filtered, and $3 \mathrm{D}$ reconstruction was used to obtain a solid digital model of the aggregate to obtain the $3 \mathrm{D}$ shape characteristics of the particles.

2.2.1. White-Light Interferometry. An EinScan-S 3D scanner was used to obtain the point cloud data (Figure 1(a)). The system operates on the principle of white-light interferometry and analyzes the interference fringes formed by the surface reflection of the measured object [15]. The point cloud data contain information on the surface geometric characteristics of the aggregate particles [16]. During the scanning process, multiple frames of interference fringe images of the aggregate surface were obtained by the chargecoupled device. Software was used to obtain the $3 \mathrm{D}$ coordinates of the scanning points of the aggregate surface in the coordinate system of the scanner (Figure 1(b)).

2.2.2. Point Cloud Registering and Denoising. After scanning the $3 \mathrm{D}$ contour surface of the aggregate test sample from multiple angles (Figure 2(a)), the iterative closest point (ICP) algorithm in the Imageware software was used to register the point cloud of multiple scans. The purpose of the ICP algorithm was to determine the rotation and shift parameters of the point cloud scans from different angles to register the dataset and obtain an optimal match for the data with different incident angles due to changes in the light source [17].

The registered dataset was imported into the PCL library to eliminate outliers and noise. This library is a large crossplatform open-source $C++$ programming library containing many algorithms and data structures related to point clouds, including point cloud acquisition, filtering, segmentation, registration, retrieval, feature extraction, recognition, tracking, surface reconstruction, and visualization [18]. The VoxelGrid filter was used for noise reduction. A 3D mesh of the aggregate particle was generated after eliminating $96 \%$ of the point cloud data (Figure 2(b)).

2.2.3. Surface Reconstruction and Solid Model. The nonuniform rational basis spline (NURBS) method in the Unigraphics NX (UG) software was used to fit the 3D mesh of the aggregate onto a NURBS surface [19]. The block generation method was used in areas of large surface changes [20]. First, the boundary line of the surface was extracted. Then, the boundary line was used to select the point set. Finally, the boundary line and the point cloud were used to fit the NURBS surface (see Figure 2(c)). After surface model fitting, merging and a Boolean operation were used to 
TABLE 1: Technical indices and chemical components of the matrix asphalt.

\begin{tabular}{|c|c|c|c|c|c|c|c|}
\hline $\begin{array}{l}\text { Test } \\
\text { item }\end{array}$ & $\begin{array}{c}\text { Penetration } \\
\left(25^{\circ} \mathrm{C}\right)\left(10^{-1} \mathrm{~mm}\right)\end{array}$ & $\begin{array}{l}\text { Softening } \\
\text { point }\left({ }^{\circ} \mathrm{C}\right)\end{array}$ & $\begin{array}{c}\text { Ductility } \\
\left(10^{\circ} \mathrm{C}\right)(\mathrm{cm})\end{array}$ & $\begin{array}{c}\text { Saturated fraction } \\
(\%)\end{array}$ & $\begin{array}{c}\text { Aromatic fraction } \\
(\%)\end{array}$ & Resin (\%) & Asphaltene (\%) \\
\hline$A 1$ & 72.6 & 48.8 & 125 & 19.23 & 31.57 & 48.50 & 0.70 \\
\hline$A 2$ & 65.4 & 45.6 & 27 & 13.45 & 44.14 & 34.61 & 7.80 \\
\hline$A 3$ & 72.1 & 44.3 & 23 & 26.50 & 23.33 & 47.26 & 2.91 \\
\hline$B 1$ & 87.3 & 47.5 & $>150$ & 26.58 & 27.44 & 45.18 & 0.80 \\
\hline$B 2$ & 89.8 & 47.1 & 111 & 14.01 & 41.75 & 35.92 & 8.32 \\
\hline B3 & 86.0 & 46.3 & 72.6 & 12.62 & 54.03 & 24.82 & 8.53 \\
\hline$C 1$ & 111.0 & 43.6 & $>150$ & 24.06 & 26.08 & 49.16 & 0.70 \\
\hline$C 2$ & 106.8 & 44.5 & $>150$ & 28.49 & 37.44 & 27.50 & 6.57 \\
\hline C3 & 102.5 & 44.9 & 101 & 16.50 & 37.73 & 31.63 & 14.14 \\
\hline
\end{tabular}

TABLE 2: Basic technical properties and mineral composition of the aggregate.

\begin{tabular}{|c|c|c|c|c|c|c|c|c|c|c|c|c|c|c|}
\hline \multirow[b]{2}{*}{ Lithology } & \multicolumn{5}{|c|}{ Technical performance } & \multicolumn{9}{|c|}{ Chemical composition } \\
\hline & $\begin{array}{c}\text { Crush } \\
\text { value } \\
(\%)\end{array}$ & $\begin{array}{c}\text { Abrasion } \\
\text { value }(\%)\end{array}$ & $\begin{array}{l}\text { Polish } \\
\text { value }\end{array}$ & $\begin{array}{c}\text { Water } \\
\text { absorption } \\
(\%)\end{array}$ & $\begin{array}{c}\text { Apparent } \\
\text { relative } \\
\text { density ( } \mathrm{g} / \\
\mathrm{cm}^{3} \text { ) }\end{array}$ & $\begin{array}{c}\mathrm{SiO}_{2} \\
(\mathrm{wt} \\
\%)\end{array}$ & $\begin{array}{l}\mathrm{Al}_{2} \mathrm{O}_{3} \\
(\mathrm{wt} \%)\end{array}$ & $\begin{array}{l}\mathrm{Fe}_{2} \mathrm{O}_{3} \\
(\mathrm{wt} \%)\end{array}$ & $\begin{array}{c}\mathrm{FeO} \\
(\mathrm{wt} \\
\%)\end{array}$ & $\begin{array}{c}\mathrm{CaO} \\
(\mathrm{wt} \\
\%)\end{array}$ & $\begin{array}{l}\mathrm{MgO} \\
(\mathrm{wt} \%)\end{array}$ & $\begin{array}{c}\mathrm{K}_{2} \mathrm{O} \\
(\mathrm{wt} \\
\%)\end{array}$ & $\begin{array}{l}\mathrm{Na}_{2} \mathrm{O} \\
(\mathrm{wt} \%)\end{array}$ & $\begin{array}{c}\mathrm{TiO}_{2} \\
\text { (wt } \\
\%)\end{array}$ \\
\hline Granite & & & 46 & & 2.654 & 70.05 & 15.11 & 1.36 & 2.04 & 1.99 & 1.07 & 2.66 & 2.08 & 0.87 \\
\hline Basalt & 1 & 8.9 & 58 & 0.63 & 2.724 & 50.43 & 16.54 & 4.43 & 2.72 & 5.80 & 2.84 & 3.03 & 4.21 & 1.07 \\
\hline Limestone & 21.5 & 19.4 & 42 & 0.72 & 2.698 & 1.67 & 0.42 & 0.28 & 0.01 & 85.78 & 0.07 & 0.31 & 0.44 & 1.01 \\
\hline
\end{tabular}

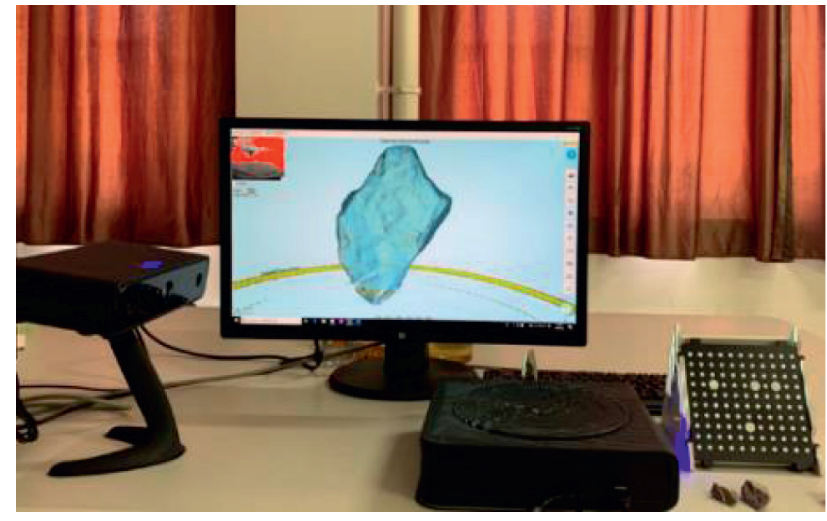

(a)

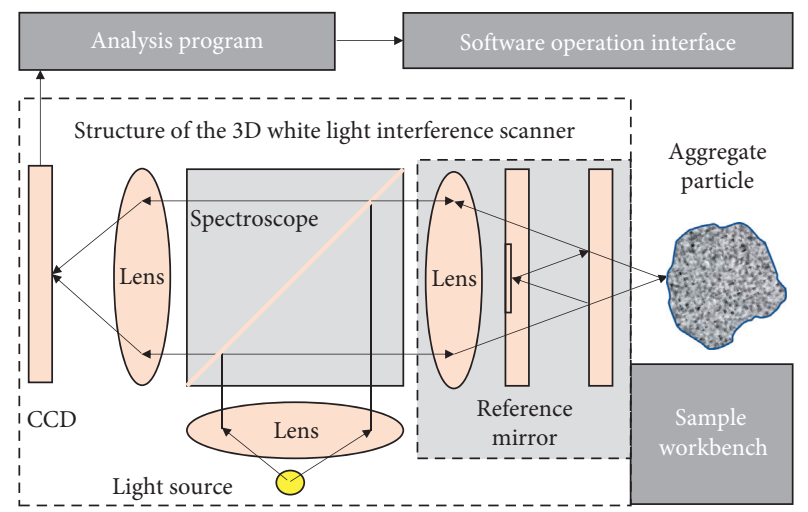

(b)

FIGURE 1: Point cloud data acquisition instrument and 3D scanning principle: (a) EinScan-S 3D scanner; (b) principle of 3D scanning technology.

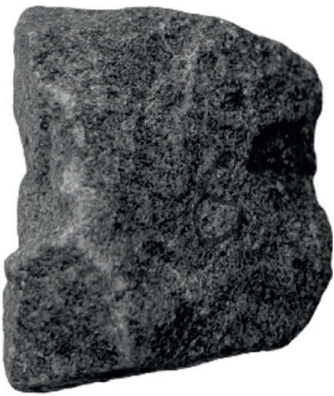

(a)

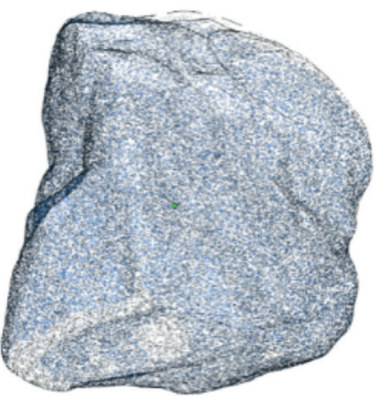

(b)

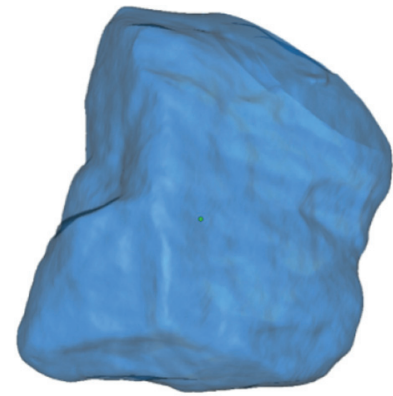

(c)

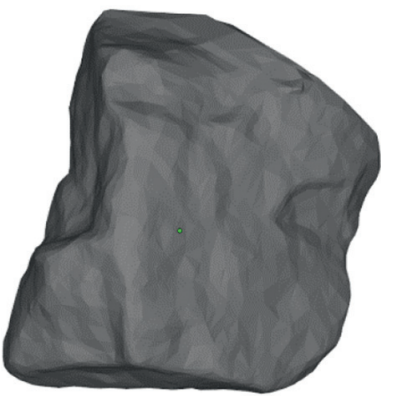

(d)

FIGURE 2: 3D reconstruction of the aggregate particle: (a) coarse aggregate particle; (b) 3D mesh; (c) fitted surface model; (d) solid model. 
generate a solid digital model that represented the $3 \mathrm{D}$ surface morphology of the aggregate particles (Figure 2(d)).

\subsection{Evaluation of 3D Morphological Characteristics of the} Aggregate. Six independent characteristic parameters were used to evaluate the 3D morphology of the aggregate particles from different angles.

\subsubsection{Evaluation of Particle Shape Characteristics}

(1) Characterization of the Particle Shape. The sphericity $S$ was used to evaluate the overall shape characteristics of the aggregate; it represents the compactness of the particle shape [21], as defined in

$$
S=\frac{S_{2}}{S_{1}}
$$

where $S_{1}$ is the surface area of the aggregate and $S_{2}$ is the surface area of a sphere with the same volume as the aggregate.

A triangulation algorithm was used to obtain the surface area and volume parameters of the aggregate. Delaunay triangular meshing was performed on the solid model of the aggregate particles in the UG software (see Figure 3(a)), and the surface area $S_{1}$ and volume $V_{1}$ of the particles were extracted. The surface area of a sphere is calculated using

$$
S_{2}=\sqrt[3]{36 \pi V_{1}^{3}}
$$

(2) Characterization of the Needle-Flake Shape. The shape factor $(S F)$ was used to describe the shape characteristics of the aggregate. The particles were needle-shaped, flake-shaped, or nearly rectangular, as defined in

$$
S F=\sqrt{\frac{l_{a} l_{c}}{l_{b}^{2}}}
$$

where $l_{\mathrm{a}}$ is the size of the long axis of the aggregate, $l_{\mathrm{b}}$ is the size of the central axis of the aggregate, and $l_{c}$ is the size of the short axis of the aggregate (Figure 3(b)).

The triaxial size of the aggregates was obtained by the Danish method [22]. A rectangular box was fitted around the 3D lattice model of the aggregates using Magics software, and the trilateral parameters $l_{\mathrm{a}}, l_{\mathrm{b}}$, and $l_{\mathrm{c}}$ with the smallest box volume were extracted (Figure 3(b)).

\subsubsection{Evaluation of the Particle's Angularity}

(1) Characterization of the Overall Angularity. The ellipsoid index $(E)$ was used to evaluate the $3 \mathrm{D}$ angularity of the aggregate, which reflects the amplitude of the peak/trough amplitude on the particle surface and the sharpness of the edges and corners [23], as defined in

$$
E=\frac{V_{1}}{V_{2}}
$$

where $V_{1}$ is the volume of the aggregate particle and $V_{2}$ is the minimum triaxial ellipsoid volume of the aggregate.

An ellipsoid with three unequal axes was fit to the solid model in the UG software, and the position of the aggregate model was adjusted to tighten the boundary of the ellipsoid. The three radii $a, b$, and $c$ of the ellipsoid with the smallest volume were obtained (see Figure 4 ). The volume of the aggregate particles was calculated using

$$
V_{2}=\frac{4 \pi a b c}{3}
$$

(2) Characterization of the Local Angularity. The principal curvature matrix $H\left(x_{0}, y_{0}\right)$ was used to evaluate the $3 \mathrm{D}$ curvature at each point on the aggregate surface, and the local angularity of the particles was obtained from the principal curvature distribution, as defined in

$$
H\left(x_{0}, y_{0}\right)=\left[\begin{array}{ll}
f_{x x}\left(x_{0}, y_{0}\right) & f_{x y}\left(x_{0}, y_{0}\right) \\
f_{y x}\left(x_{0}, y_{0}\right) & f_{y y}\left(x_{0}, y_{0}\right)
\end{array}\right],
$$

where $H\left(x_{0}, y_{0}\right)$ is a second-order Hayes matrix, $f_{X X}\left(x_{0}, y_{0}\right)=2 e, f_{X Y}\left(x_{0}, y_{0}\right)=f_{Y X}\left(x_{0}, y_{0}\right)=d$, and $f_{Y Y}\left(x_{0}, y_{0}\right)=2 g$.

Each element in the matrix was the second derivative of the fitting function $z=f(x, y)$ of the 7-vertical miniature surface around the $j$ th point in Figure 5(a), as defined in

$$
\begin{aligned}
z= & f(x, y) \approx a+b\left(x-x_{0}\right)+c\left(y-y_{0}\right) \\
& +d\left(x-x_{0}\right)\left(y-y_{0}\right)+e\left(x-x_{0}\right)^{2}+g\left(y-y_{0}\right)^{2},
\end{aligned}
$$

where $a, b$, and $c$ are the vertices of the $i^{\text {th }}$ triangle in Figure 5(a) and $d, e$, and $g$ are the undetermined coefficients.

By substituting the 3D lattice data with the spatial coordinates of the aggregate particles in equation (7), seven linear equations with six unknowns were obtained by the least-squares method. The characteristics of the matrix were obtained by equation (6) after the solution was obtained. The value and the eigenvector were used as the principal curvature and the principal curvature direction at point $j$ of the aggregate surface.

\subsubsection{Evaluation of Particle Roughness Characteristics}

(1) Evaluation Index of Surface Roughness. The joint roughness coefficient (JRC) recommended by the International Society of Rock Mechanics was used as the evaluation index of the surface texture roughness of the rock aggregate [24]. In geotechnical engineering research, roughness is often used to analyze the correlations between the rock surface profile and the interface mechanics and seepage characteristics [25]. In road engineering, the roughness coefficient is an important index to analyze the correlation between asphalt-aggregate adhesion and the surface texture roughness of aggregate particles. Barton (1977) presented 10 typical rock surface contours with values ranging from 0 to 20 obtained from experiments to evaluate the JRC value [26], as shown in Table 3. 


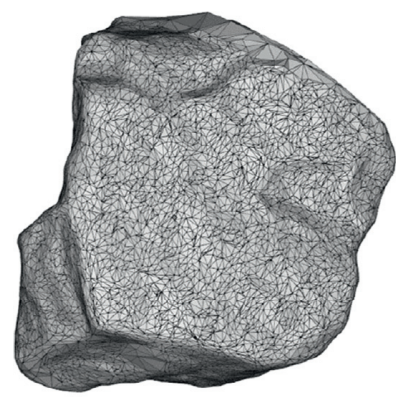

(a)

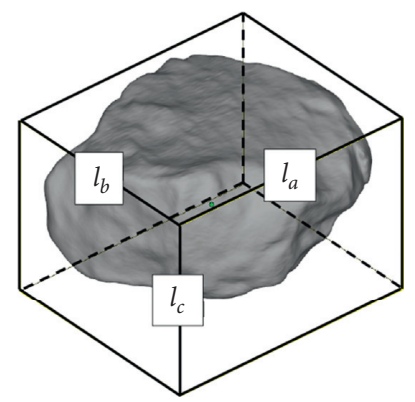

(b)

Figure 3: Calculation of the shape index parameters: (a) triangular meshing of the surface; (b) circumscribed triaxial ellipsoid of the aggregate.
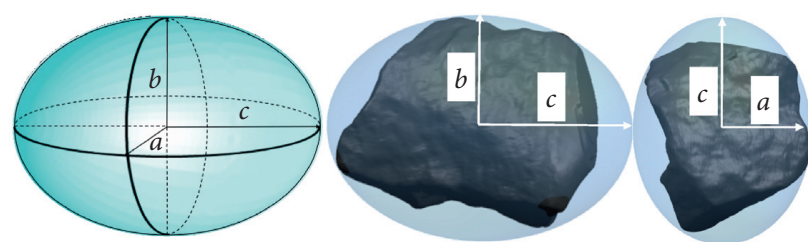

FIgURE 4: The circumscribed ellipsoid of the aggregate particles.

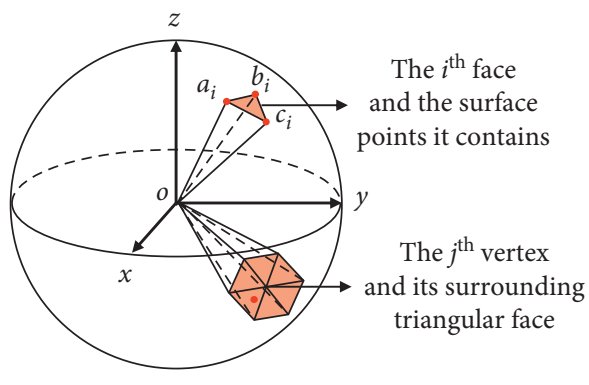

(a)

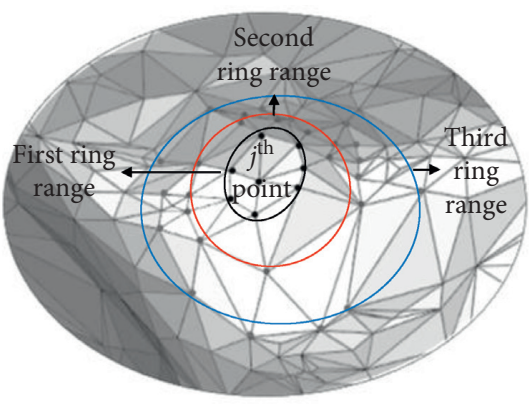

(b)

FIGURE 5: Edge and angle determination of the aggregate particles: (a) calculation of the surface curvature of the aggregate; (b) relationship between the triangular network model and the ring neighborhood.

TABLE 3: Barton standard roughness contours.

\begin{tabular}{l} 
Value range of $J R C$ \\
\hline $0 \sim 2$ \\
$2 \sim 4$ \\
$4 \sim 6$ \\
$6 \sim 8$ \\
$8 \sim 10$ \\
$10 \sim 12$ \\
$12 \sim 14$ \\
$14 \sim 16$ \\
$16 \sim 18$ \\
$18 \sim 20$
\end{tabular}

(2) Calculation Method of the Roughness of 2D Contour. The regression equation of the relationship between the geometric characteristic parameters and roughness proposed by
Tse and Crude was used to calculate the $2 \mathrm{D}$ roughness $\left(J R C^{2 \mathrm{D}}\right)$ of the surface profile of rock materials and is defined as follows [27]: 


$$
J C R=32.2+32.47 \lg Z_{2}
$$

When 3D point cloud data are used to calculate the roughness of the $2 \mathrm{D}$ contour of an aggregate surface, the characteristic parameter $Z_{2}$ of contour slope can be approximately expressed as [28]

$$
\begin{aligned}
Z_{2} & =\sqrt{\frac{1}{L} \sum_{i=1}^{n-1} \frac{\left(z_{i+1}-z_{i}\right)^{2}}{x_{i+1}-x_{i}}} \\
L & =\sum_{i=1}^{n-1}\left(x_{i+1}-x_{i}\right),
\end{aligned}
$$

where $L$ is the total length of the $2 \mathrm{D}$ profile contour line, $x_{i}$ and $z_{i}$ are the point cloud coordinates on the contour line, and $n$ is the number of samples (see Figure 6).
(3) Calculation Method of the Roughness of 3D Contours. The $3 \mathrm{D}$ roughness $J R C^{3 \mathrm{D}}$ of the local area of the particle surface can be analyzed by considering the spatial characteristics of the $3 \mathrm{D}$ contour surface of the aggregate (see Figure $7(\mathrm{a})$ ). It is assumed that the coordinates of the point cloud on the rough surface of the aggregate are continuous [29]. The root mean square $Z_{2 s}$ of the $3 \mathrm{D}$ characteristic parameter of the relative height fluctuation can be calculated as follows:

$$
Z_{2 s}=\left\{\frac{1}{L_{x} L_{y}} \int_{0}^{L_{s}} \int_{0}^{L_{y}}\left[\left(\frac{\partial z(x, y)}{\partial x}\right)^{2}+\left(\frac{\partial z(x, y)}{\partial y}\right)^{2}\right] \mathrm{d} x \mathrm{~d} y\right\}^{1 / 2}
$$

When $3 \mathrm{D}$ point cloud data are used to calculate the $J R C^{3 \mathrm{D}}$ of an aggregate surface, the approximate formula is as follows:

$$
Z_{2 s}=\left\{\frac{1}{(N-1)(N-1)}\left[\frac{1}{\Delta x^{2}} \sum_{j=1}^{N_{X}-1} \sum_{i=1}^{N_{Y}-1} \frac{\left(Z_{i+1, j+1}-z_{i, j+1}\right)^{2}+\left(Z_{i+1, j}-z_{i, j}\right)^{2}}{2}\right]+\left[\frac{1}{\Delta y^{2}} \sum_{j=1}^{N_{Y}-1} \sum_{i=1}^{N_{X}-1} \frac{\left(Z_{i+1, j+1}-z_{i, j+1}\right)^{2}+\left(Z_{i+1, j}-z_{i, j}\right)^{2}}{2}\right]\right\}^{1 / 2}
$$

where $L_{x}$ and $L_{y}$ are the length of the sample lines in the $X$ axis and $Y$-axis directions, respectively, of the analysis area on the aggregate surface; $N_{x}$ and $N_{y}$ are the number of point clouds in the $X$-axis and $Y$-axis directions, respectively, of the analysis area; $\Delta x$ and $\Delta y$ are the sample spacing of the point clouds in the $X$-axis and $Y$-axis directions, respectively; and $Z_{i}$ and $Z_{i+1}$ are the coordinates of the $i^{\text {th }}$ point and the $(i+1)^{\text {th }}$ point in the $Z$-axis direction of the roughness height, respectively. The parameters are shown in Figure 7(b).

(4) Method to Assess the Surface Roughness Change of the Aggregate. An aggregate polishing test was designed to test the accuracy of the roughness coefficient $J R C$ to determine then changes in the aggregate surface roughness. In the test, 1200\# carborundum with $95 \%$ alumina content was used as an abrasive, and a vibrating polishing machine was used to change the mesostructures of the surface textures of the four aggregates with different lithologies. The steps of the aggregate polishing test were as follows:

(1) After soaking the abrasive in water, it was drained in a basket and placed into the vibrating polishing machine

(2) The power was turned on, and the wet aggregate was placed in the abrasive in the vibrating polishing machine and was polished from different directions

(3) After the carborundum was uniformly added to the mixture, the desired polishing time was set; after the polishing test, the carborundum in the mixture was washed off with clean water

At the end of each polishing test, the point cloud data of the particle surface were collected again, and the changes in the aggregate surface roughness under different polishing conditions were compared and analyzed.

2.4. Quantitative Evaluation of the Adhesion between Asphalt and Aggregate. Asphalt and aggregate samples were obtained after the boiling test using a self-developed image acquisition system to evaluate the difference in adhesion between the asphalt and aggregate quantitatively. This system was based on the traditional evaluation method of the boiling test. Image processing software was used to determine the stripping rate of the asphalt quantitatively.

2.4.1. Test Method and Evaluation Indices of Adhesion between the Asphalt and Mixture. An improvement was made of the adhesion test between asphalt and coarse aggregate based on T0616-1993 specified in the Chinese specification of JTG E20-2011. First, 5\% NaCl solution was used instead of pure water to improve the ability to distinguish the difference in adhesion of asphalt film on the surface of three kinds of lithologic asphalt. Second, the stripping rate of asphalt on the aggregate surface was determined using digital image processing to obtain a quantitative measure of the difference in adhesion between asphalt and aggregate quantitatively. Finally, since the adhesion grade 5 of the traditional boiling method could not distinguish slight differences in adhesion between asphalt and aggregate, the classification standard of 10 grade was proposed to reduce the difference in the asphalt spalling rate between different adhesion grades, as shown in Table 4 .

The test conditions should be identical in repeated tests to ensure the accuracy and reliability of the results. Therefore, the following measures were used. 


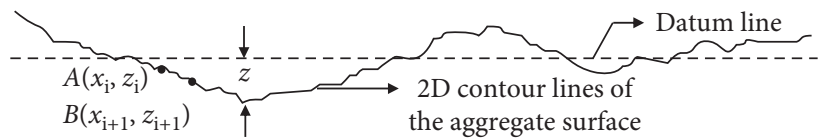

FiguRE 6: 2D profile of the aggregate surface.

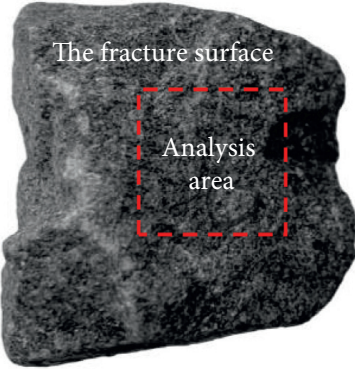

(a)

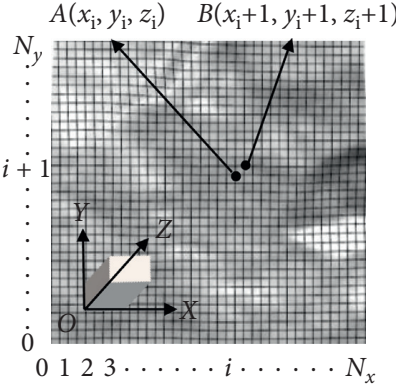

(b)

FIGURE 7: 3D contour surface of the aggregate: (a) analysis area; (b) contour surface point cloud.

TABLE 4: 10-level grading standard for asphalt adhesion.

\begin{tabular}{|c|c|c|c|c|c|c|c|c|c|c|c|}
\hline \multirow[b]{2}{*}{$\begin{array}{l}\text { Adhesion } \\
\text { classification }\end{array}$} & $\begin{array}{l}\text { Adhesion } \\
\text { grade }\end{array}$ & 10 & 9 & 8 & 7 & 6 & 5 & 4 & 3 & 2 & 1 \\
\hline & $\begin{array}{l}\text { Stripping } \\
\text { rate/\% }\end{array}$ & $\leq 5$ & $5 \sim 10$ & $10 \sim 15$ & $\begin{array}{c}15 \\
\sim \\
20\end{array}$ & $\begin{array}{c}20 \\
\sim \\
30\end{array}$ & $\begin{array}{c}30 \\
\sim \\
40\end{array}$ & $\begin{array}{c}40 \\
\sim \\
50\end{array}$ & $\begin{array}{l}50 \\
\sim \\
60\end{array}$ & $\begin{array}{c}60 \\
\sim \\
70\end{array}$ & $\geq 70$ \\
\hline \multicolumn{2}{|c|}{ Exfoliation description } & $\begin{array}{l}\text { Asphalt film } \\
\text { is intact }\end{array}$ & $\begin{array}{l}\text { Very small amount } \\
\text { of peeling off at the } \\
\text { edges }\end{array}$ & $\begin{array}{l}\text { A small amount of } \\
\text { exfoliation on some } \\
\text { surfaces }\end{array}$ & \multicolumn{2}{|c|}{$\begin{array}{l}\text { The } \\
\text { asphalt } \\
\text { film has } \\
\text { partially } \\
\text { peeled } \\
\text { off, and } \\
\text { the } \\
\text { exposed } \\
\text { area of } \\
\text { the } \\
\text { aggregate } \\
\text { surface is } \\
15 \% \text { to } \\
30 \% .\end{array}$} & \multicolumn{2}{|c|}{$\begin{array}{l}\text { Many } \\
\text { asphalt } \\
\text { films } \\
\text { have } \\
\text { peeled } \\
\text { off, and } \\
\text { the } \\
\text { exposed } \\
\text { area of } \\
\text { the }\end{array}$} & $\begin{array}{r}\text { Ma } \\
\text { aspl } \\
\text { fil } \\
\text { ha } \\
\text { pee } \\
\text { off, } \\
\text { th } \\
\text { expc } \\
\text { are } \\
\text { th } \\
\text { aggre } \\
\text { surfa } \\
30 \% \\
60\end{array}$ & $\begin{array}{l}\text { iny } \\
\text { halt } \\
\text { ns } \\
\text { ve } \\
\text { led } \\
\text { and } \\
\text { he } \\
\text { sed } \\
\text { of } \\
\text { of } \\
\text { egate } \\
\text { ce is } \\
6 \text { to } \\
\%\end{array}$ & $\begin{array}{c}\text { The exposed area of the } \\
\text { aggregate surface } \\
\text { exceeds } 70 \%\end{array}$ \\
\hline
\end{tabular}

(1) Shape of the Aggregate. The shape of the aggregate has a substantial influence on the test results; thus, an aggregate with regular and compact appearance should be selected for the test.

(2) Temperature of the Asphalt. When aggregates are immersed in asphalt for adsorption, the asphalt should be maintained at a constant temperature to reduce the change in adsorption capacity caused by differences in asphalt temperature.

(3) Slight Boiling State of Water. In this test, it was stipulated that the slight boiling state of water meant that local turbulence occurred on the surface of the liquid, and large bubbles were released between the bottom of the beaker and ruptured when reaching the surface of the liquid.
(4) Aggregate Immersion Position. It is recommended to maintain the distance between the top of the aggregate and the liquid surface at about $2 \mathrm{~cm}$.

(5) Exfoliated Asphalt Treatment. When the asphalt is peeled off from the aggregate surface, it floats on top of the liquid. The asphalt particles should be removed with a piece of paper to prevent the exfoliated asphalt from being attached to the aggregate again when the aggregate is removed at the end of the test.

2.4.2. Quantitative Analysis Method to Determine the Stripping Rate of the Asphalt Film. The 3D point cloud data of the aggregate particles covered by the bitumen membrane and the volume data of the aggregate solid model before and 
after the boiling method were obtained. The change in the volume of the aggregate particles before and after the boiling test was determined using equation (13) to quantify the stripping rate $\mathrm{P}$ of the asphalt film on the surface of the aggregate:

$$
P=1-\frac{V_{3}-V_{1}}{V_{2}-V_{1}},
$$

where $V_{1}$ is the original volume of the aggregate, $V_{2}$ is the volume of the particles coated with asphalt, and $V_{3}$ is the volume of the aggregate after the bitumen film is partially peeled off in the boiling test.

\section{Results and Discussion}

3.1. Evaluation of the 3D Morphology Index of the Aggregate Particles. The solid digital model of the aggregate particles was reconstructed using $3 \mathrm{D}$ point cloud data, and six independent characteristic parameters were used to characterize the $3 \mathrm{D}$ morphology of the aggregate particles at different levels. The applicability of the parameters is discussed to determine the evaluation standard of the $3 \mathrm{D}$ morphology of the aggregate test samples under the experimental conditions of this study.

\subsubsection{Shape Evaluation Based on Sphericity and Shape Factor.} The $S$ and $S F$ were used to evaluate the shape characteristics of the aggregate samples; the results are shown in Table 5.

The evaluation result shows that the $S$ of the aggregate samples ranges from 0.68 to 0.89 . The particles with low $S$ values were narrow or flaky, whereas the shape of the particles with high $S$ values was nearly equiaxed rectangular or ellipsoidal. Under the experimental conditions of this study, the shape of the coarse aggregate was compact, and the crushing resistance was relatively strong when $S \geq 0.76$.

The $S F$ of the aggregate samples ranged from 0.67 to 1.43 . The $S F$ values of particles with different shapes were in the following order: acicular particles $>$ normal particles $>$ flat particles. Under the experimental conditions of this study, the coarse aggregates were flake-shaped particles when $S F<0.80$, well-shaped particles when $0.80 \leq S F \leq 1.20$, and needle-shaped particles when $S F>1.20$.

The results of the quantitative $3 \mathrm{D}$ shape analysis of eight aggregate samples with different shapes are shown in Table 6.

The test results show that the $S$ can be used to describe the compactness of the aggregate. It is suitable for calculating the content of poorly shaped particles in coarse aggregate but cannot distinguish the shape properties of particles. In contrast, the $S F$ can characterize the needle-flake shape of the aggregate; thus, it is suitable for the quantitative evaluation of the $3 \mathrm{D}$ shape characteristics of coarse aggregate particles.

3.1.2. Angularity Evaluation Based on the Ellipsoid Index and Principal Curvature. The $E$ was used to evaluate the $3 \mathrm{D}$ angularity of the aggregate, and the roundness of the particles was evaluated by comparing it with the evaluation standard of gravel and gravel morphology proposed by Powers [30]. The results are shown in Table 7.

The evaluation result shows that the $E$ of the aggregate samples ranged from 0.68 to 0.89 . The particles with a low $E$ value had relatively more sharp edges and corners, with needle-like characteristics. The particles with a high $E$ value had relatively few edges and corners and a gentle profile, and most were well-shaped and near-rectangular. Under the experimental conditions of this study, the aggregates had sharp edges that could be easily broken when $E \leq 0.71$, angular- and subangular-shaped edges, which formed a chain-type aggregate skeleton structure with good load transfer performance in asphalt concrete when $0.71 \leq E<0.79$ and $0.79 \leq E \leq 0.88$, and a subcircular shape with rounded edges and corners when $E>0.88$. Therefore, there should be no sharp angular, round, and spherical aggregate particles in road aggregates.

The ellipticity and roundness of the eight aggregates in Table 2 were evaluated. The vertices and ridges on the surface of the aggregate Delaunay triangulation model and the range of the three rings were identified by the secondary development program in Unigraphics NX. The results are shown in Table 8.

The test results show that the principal curvature of the aggregate particle corner region was relatively large, and the principal curvature of the fracture surface was relatively small. The particle surface edge and corner region identified by the secondary development program of the principal curvature distribution was consistent with the visual observations.

\subsubsection{Texture Evaluation Based on Roughness}

(1) $2 D$ Roughness of the Aggregate Fracture Surface. The texture of the aggregate fracture surface was evaluated by 2D contour line roughness; the analysis area (Figure $7(\mathrm{a})$ ) of the aggregate fracture surface was $10 \times 10 \mathrm{~mm}$. Ten cross-sections were used in the $X$ - and $Y$-axis directions at equal intervals of $1.0 \mathrm{~mm}$. The point coordinates of the contour lines were extracted from the $3 \mathrm{D}$ point cloud model of the aggregate, and the $2 \mathrm{D}$ contour line was obtained drawn. The $J R C^{2 \mathrm{D}}$ value of the contour lines was determined based on the functional relationships described in equations (8) and (9) and using a MATLAB program. The results are shown in Figure 8 .

The profile roughness of the different sections was different, with small curvature variations; anisotropy of the roughness was observed, and there was no significant difference in roughness between different directions. The randomness of the selection of the cross-sections leads to deviations in the roughness when the $J R C^{2 \mathrm{D}}$ index is used to characterize the roughness of the aggregates. Therefore, the $J R C^{2 \mathrm{D}}$ cannot describe the overall morphology of the aggregate surface, and it is necessary to use the $J R C^{3 \mathrm{D}}$ to characterize the spatial characteristics of the aggregate.

(2) 3D Roughness of the Aggregate Fracture Surface. The texture of the aggregate fracture surface was evaluated using 
TABLE 5: Shape feature of the aggregate samples.

\begin{tabular}{|c|c|c|c|c|c|c|c|c|c|}
\hline \multirow{2}{*}{ Lithology } & \multirow{2}{*}{ Number of aggregate samples } & \multicolumn{4}{|c|}{ Sphericity $S$} & \multicolumn{4}{|c|}{ Shape factor $S F$} \\
\hline & & Max & Min & Average & Standard deviation & Max & Min & Average & Standard deviation \\
\hline Granite & 50 & 1.35 & 0.68 & 0.97 & 0.91 & 0.69 & 0.86 & 14.1 & 9.7 \\
\hline Basalt & 50 & 1.36 & 0.73 & 1.00 & 0.88 & 0.67 & 0.84 & 15.7 & 11.3 \\
\hline Limestone & 50 & 1.43 & 0.67 & 0.99 & 0.89 & 0.68 & 0.82 & 18.3 & 11.1 \\
\hline
\end{tabular}

TABLE 6: Evaluation of the shape characteristics of typical aggregate samples.

\begin{tabular}{|c|c|c|c|c|c|c|c|c|}
\hline No. & 1 & 2 & 3 & 4 & 5 & 6 & 7 & 8 \\
\hline Aggregate particles & & & & & & & & \\
\hline Solid model of agg & & & & & & & & \\
\hline Sphericity index S & 0.68 & 0.73 & 0.82 & 0.89 & 0.88 & 0.79 & 0.76 & 0.72 \\
\hline Shape factor $S F$ & 1.37 & 1.23 & 1.10 & 1.01 & 0.99 & 0.84 & 0.78 & 0.71 \\
\hline
\end{tabular}

TABLE 7: The edge and angle feature of the aggregate samples.

\begin{tabular}{|c|c|c|c|c|c|c|c|c|c|c|c|}
\hline \multirow{3}{*}{ Lithology } & \multirow{3}{*}{$\begin{array}{c}\text { Number of } \\
\text { aggregate samples }\end{array}$} & \multicolumn{10}{|c|}{ Angularity characteristics of aggregate particles } \\
\hline & & \multicolumn{4}{|c|}{ Ellipsoid index E } & \multicolumn{6}{|c|}{ Roundness level/grain } \\
\hline & & Max & Min & Average & $\begin{array}{l}\text { Standard } \\
\text { deviation }\end{array}$ & $\begin{array}{l}\text { Sharp } \\
\text { angular }\end{array}$ & Angular & Subangular & Subrounded & Rounded & Rotund \\
\hline Granite & 20 & 0.91 & 0.69 & 0.85 & 0.0451 & 1 & 4 & 11 & 3 & 1 & 0 \\
\hline Basalt & 20 & 0.88 & 0.67 & 0.83 & 0.0467 & 1 & 12 & 6 & 1 & 0 & 0 \\
\hline Limestone & 20 & 0.89 & 0.68 & 0.81 & 0.0563 & 1 & 7 & 11 & 1 & 0 & 0 \\
\hline
\end{tabular}

TABLE 8: Evaluation of the edge and angle characteristics of typical aggregate samples.

\begin{tabular}{|c|c|c|c|c|c|c|c|c|}
\hline No. & 1 & 2 & 3 & 4 & 5 & 6 & 7 & 8 \\
\hline Ellipsoid index $E$ & 0.68 & 0.73 & 0.77 & 0.84 & 0.89 & 0.83 & 0.75 & 0.69 \\
\hline $\begin{array}{l}\text { Local angular region } \\
\text { identification } \\
\text { of } \\
\text { aggregate }\end{array}$ & & & & & & & & \\
\hline Roundness level & $\begin{array}{c}\text { Sharp } \\
\text { angular }\end{array}$ & Angular & Angular & Subangular & Subrounded & Subangular & Angular & Sharp angular \\
\hline
\end{tabular}
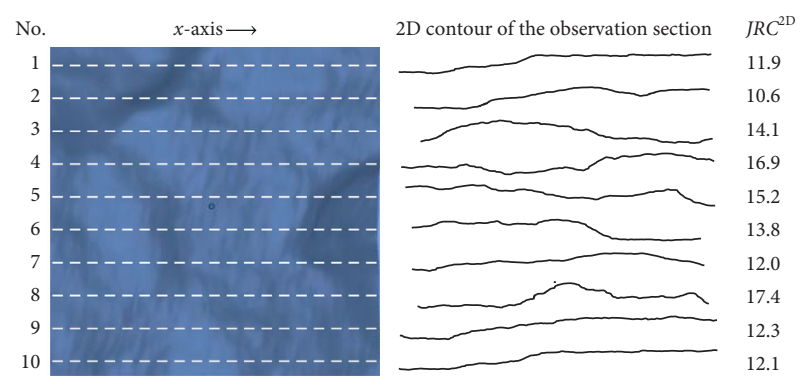

(a)

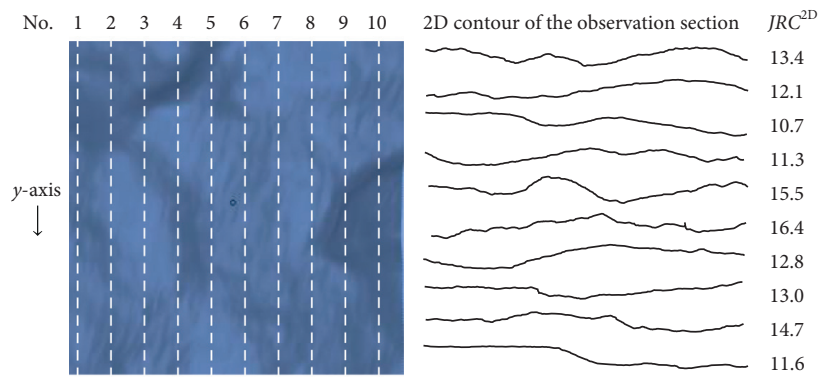

(b)

FIgURE 8: 2D roughness of the contour lines of the aggregate surface: (a) 2D profile position distribution along the $X$-axis; (b) 2D profile position distribution along the $Y$-axis. 
the $J R C^{3 \mathrm{D}}$. The point cloud data in the analysis area (Figure $7(\mathrm{a})$ ) of the aggregate fracture surface were sampled at intervals of $10 \times 10 \mathrm{~mm}$, i.e., $\Delta x=\Delta y=0.25 \mathrm{~mm}$. Equation (11) was used to calculate the characteristic parameter $Z_{2 s}$, and the $J R C^{3 \mathrm{D}}$ value of the analysis area was then calculated on the functional relationships described in equations (8), as shown in Figure 9.

The aggregate polishing test was used to change the mesostructure of the surface textures of the four aggregates with different lithologies and test the accuracy of the $J R C^{3 \mathrm{D}}$ in describing the changes in aggregate surface roughness. The results are reported in Table 9. The roughness trend of the aggregate test samples with different lithologies for different polishing times is shown in Figure 10.

The test results show that the initial average roughness of the fracture surface of the limestone aggregate sample was the highest, followed by basalt and granite. The surface roughness of the aggregates with different lithologies decreased, and the texture of the aggregates became smoother with an increase in the polishing time. The average roughness of the fracture surface of limestone decreased the most, followed by basalt and granite. The results show that the surface wear resistance of the granite aggregate was substantially higher than that of the limestone aggregate, and that of the basalt aggregate was in between. This result was consistent with the attenuation of the mechanical index of road aggregate in practical engineering.

The test results demonstrate that the $J R C^{3 \mathrm{D}}$ has a high sensitivity to the mesostructure changes in the aggregate surface texture and that this coefficient can be used as an evaluation index of the $3 \mathrm{D}$ roughness of the aggregate fracture surface. However, when 3D point cloud data of the contour surface are used to evaluate the roughness characteristics of the particles, it is necessary to consider that large changes in the curvature in the edge and corner regions will lead to inaccurate evaluation results. Thus, the edge and corner regions on the surface of the solid model were identified by the secondary development program in Unigraphics NX. Subsequently, the 3D coordinates on the surface of these regions were eliminated in the mesh model. The remaining valid point cloud data of the aggregate surface were used to calculate the $J R C^{3 \mathrm{D}}$ of the aggregate surface.

3.2. Evaluation of the Stripping Rate and Adhesion Level. Adhesion tests were conducted on the 3 types of aggregates and 9 types of matrix asphalt. The aggregate samples with different lithology were divided into nine groups, with five aggregates in each group. The average stripping rate was calculated after the test with the same asphalt, and the adhesion grades were determined according to the classification standards in Table 4. The evaluation results are shown in Table 10.

The test results show that the stripping rate of the asphalt film can be determined quantitatively by measuring the volume change of the aggregate before and after the adhesion test using 3D scanning technology. The adhesion level between the asphalt and the aggregate can be determined by increasing the boiling time and adopting a 10-level grading standard.
3.3. Influence of the Aggregate Lithology on the Adhesion Level. The average values of the stripping rate of the 3 types of aggregates and 9 types of asphalt in the improved water boiling method and adhesion test are shown in Figure 11.

The surface of alkaline limestone aggregate contains alkaline active substances, which react with the acidic components in the asphalt to form a chemical bond. The chemical adsorption occurring between the two materials on the contact surface prevents the asphalt film from being damaged or peeled off during the boiling test. When acidic minerals are in contact with acidic asphalt, chemical adsorption does not readily occur near the contact surface; thus, the adhesion level of the asphalt and granite is low, and the stripping rate of the asphalt film is high in high-temperature water. The content of $\mathrm{SiO}_{2}$ in the basalt is between that of limestone and granite because basalt is neutral and weakly alkaline. Therefore, the adhesion level between asphalt and the basalt aggregate near the contact surface is lower than that of limestone but significantly higher than that of granite.

\subsection{Influence of the Asphalt Components on Adhesion.} The correlation between the saturated fraction, aromatic fraction, resin content, and asphaltene content ( $S, \mathrm{Ar}, R, \mathrm{As})$ of the asphalt and the adhesion levels of the aggregates with different lithology is shown in Figure 12.

As shown in Figure 12, the contents of the resin and asphaltene in the asphalt have the largest influence on the level of adhesion between the asphalt and the alkaline limestone aggregate, and the resin content has the largest influence on the level of adhesion between the asphalt and the weakly alkaline basalt aggregate. The contents of the four components in the asphalt have poor correlations with the level of adhesion between the asphalt and the acidic granite aggregate.

In terms of the chemical composition of the raw materials, the acidic compounds in the asphalt include the resin and asphaltene components, which can be chemically adsorbed to the active alkali components on the surface of the limestone aggregate and are not easily desorbed. The silica content in the basalt aggregate increases, the active alkali components on the surface decrease, and the ability to adsorb acid compounds chemically in the asphalt decreases. Due to the lack of bonding groups on the surface of the acidic granite aggregate, weak physical adsorption occurs due to the viscosity of the colloid and asphaltene when it comes into contact with the asphalt. Therefore, when the asphalt film on the surface of the granite aggregate is softened by heat in the boiling test, parts with poor adhesion will be damaged. Subsequently, the damaged part will cause additional damage to the asphalt membrane, and shedding occurs due to the water infiltration.

From the perspective of the charge properties of the raw materials, the following chemical reactions can occur after water infiltration between calcium carbonate on the surface of the alkaline limestone aggregate and silica on the surface of the acidic aggregate: 


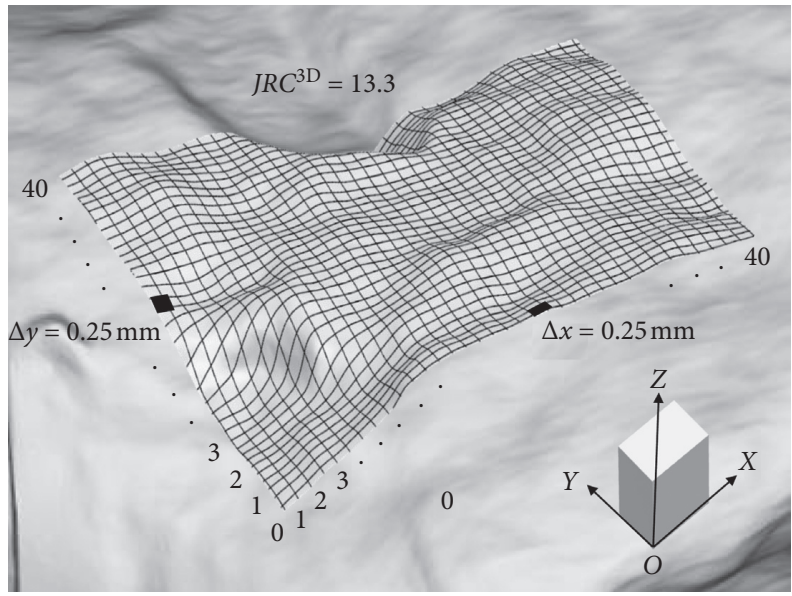

FiguRE 9: 3D roughness of the contour surface of the aggregate.

TABLE 9: The change in the roughness with increasing polishing time.

\begin{tabular}{lcccccccccc}
\hline \multirow{2}{*}{ Polishing time $(\mathrm{h})$} & \multirow{2}{*}{ Number of aggregate samples } & \multicolumn{3}{c}{ Granite } & \multicolumn{3}{c}{ Basalt } & \multicolumn{2}{c}{ Limestone } \\
& & Max & Min & Average & Max & Min & Average & Max & Min & Average \\
\hline 0.0 & 20 & 13.6 & 9.7 & 11.5 & 15.7 & 11.0 & 13.1 & 18.3 & 11.1 & 15.8 \\
0.5 & 20 & 13.1 & 9.5 & 11.0 & 15.1 & 10.5 & 12.4 & 16.01 & 9.63 & 14.1 \\
1.0 & 20 & 12.9 & 9.2 & 10.7 & 14.4 & 10.2 & 12.1 & 14.85 & 8.77 & 12.4 \\
1.5 & 20 & 12.8 & 9.1 & 10.5 & 13.9 & 10.0 & 11.8 & 14.09 & 8.08 & 11.1 \\
2.0 & 20 & 12.5 & 9.2 & 10.4 & 13.3 & 10.0 & 11.4 & 13.50 & 7.11 & 9.8 \\
\hline
\end{tabular}

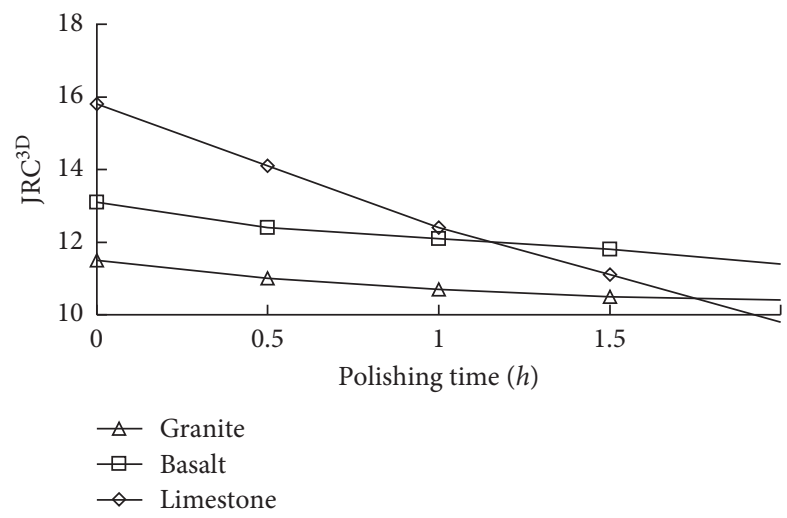

Figure 10: The roughness trend of different aggregate types with increasing polishing time.

TABLE 10: Stripping rate of asphalt on the aggregate surface and the adhesion level.

\begin{tabular}{|c|c|c|c|c|c|c|c|c|c|c|}
\hline \multirow{2}{*}{ Aggregate type } & \multirow{2}{*}{ Evaluation index } & \multicolumn{9}{|c|}{ Asphalt type } \\
\hline & & $A 1$ & $A 2$ & A3 & $B 1$ & $B 2$ & B3 & $C 1$ & $C 2$ & C3 \\
\hline \multirow{3}{*}{ Granite } & Average stripping rate (\%) & 57.99 & 76.35 & 70.24 & 60.38 & 70.33 & 82.07 & 69.42 & 76.58 & 87.11 \\
\hline & Standard deviation & 13.2223 & 5.9694 & 3.7577 & 4.8376 & 5.5874 & 6.5320 & 3.4375 & 7.0964 & 2.9095 \\
\hline & Adhesion level & 3 & 1 & 1 & 2 & 1 & 1 & 2 & 1 & 1 \\
\hline \multirow{3}{*}{ Basalt } & Average stripping rate (\%) & 21.73 & 46.82 & 30.34 & 19.68 & 59.22 & 61.69 & 23.34 & 35.71 & 57.54 \\
\hline & Standard deviation & 9.4473 & 7.0265 & 6.8855 & 5.8632 & 7.9738 & 6.9951 & 6.8161 & 8.0227 & 7.8151 \\
\hline & Adhesion level & 6 & 4 & 5 & 7 & 3 & 2 & 6 & 5 & 3 \\
\hline \multirow{3}{*}{ Limestone } & Average stripping rate (\%) & 17.65 & 25.62 & 17.31 & 18.77 & 27.31 & 34.99 & 16.84 & 31.06 & 31.03 \\
\hline & Standard deviation & 6.0636 & 5.0029 & 5.8597 & 6.2877 & 6.4361 & 7.8059 & 7.7715 & 8.1286 & 8.0201 \\
\hline & Adhesion level & 7 & 6 & 7 & 7 & 6 & 5 & 7 & 5 & 5 \\
\hline
\end{tabular}




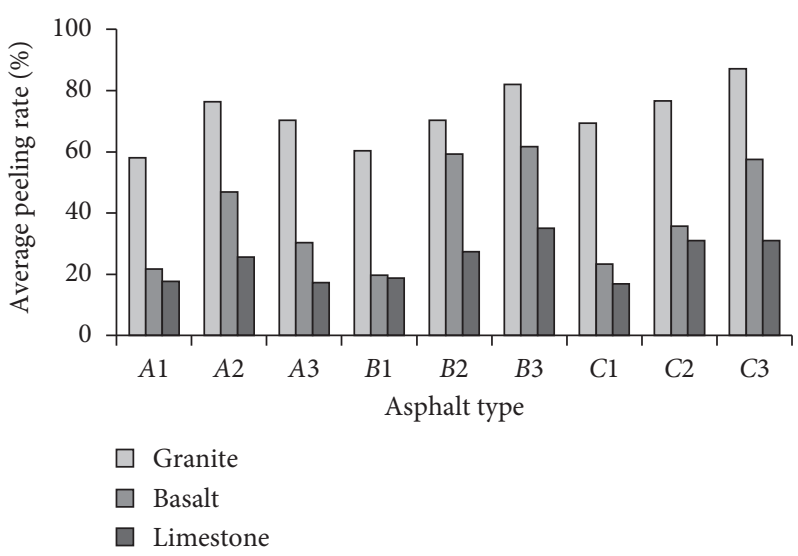

FIGURE 11: Stripping rate of the asphalt on the aggregate surface and the adhesion grade.

$$
\begin{array}{r}
\mathrm{CaCO}_{3}+\mathrm{H}_{2} \mathrm{O}=\mathrm{Ca}^{2+}+\mathrm{HCO}_{3^{-}}+\mathrm{OH}^{-} \\
\mathrm{CaCO}_{3}+\mathrm{H}_{2} \mathrm{O}+\mathrm{CO}_{2}=\mathrm{Ca}^{2+}+2 \mathrm{HCO}_{3^{-}} \\
\mathrm{SiO}_{2}+\mathrm{H}_{2} \mathrm{O}=\mathrm{H}_{2} \mathrm{SiO}_{3}=\mathrm{HSiO}_{3^{-}}+\mathrm{H}^{+}=\mathrm{SiO}_{3}^{2-}+2 \mathrm{H}^{+}
\end{array}
$$

Asphaltic acid and bituminous anhydride are active anionic surface substances, which can produce anisotropic attraction and physical adsorption between asphaltene acid and the positive potential on the surface of the alkaline aggregate. However, when the asphalt is in contact with acid granite aggregate, a repulsive force occurs on the contact surface that is not conducive to adsorption. When asphalt is in contact with weakly alkaline basalt aggregate, in addition to the orientation force of the anisotropic attraction between polar molecules, the induction force between polar and nonpolar molecules and the dispersion force between nonpolar molecules will occur. The greater the polarity, the more important the role of the orientation force is. Therefore, the correlation between the polar components in the asphalt and the level of adhesion of the asphalt to the aggregates is highest for the limestone aggregates, followed by the basalt aggregates and the granite aggregates.

3.5. Influence of 3D Morphology of the Aggregates on the Adhesion Level. The correlation between the shape, angularity, and surface roughness indicators of the particles and the adhesion level is analyzed.

It is observed in Figure 13 that for the acid granite aggregates, the surface roughness has the highest correlation with the adhesion level of the asphalt on the aggregate surface, the angularity of the particles has a certain effect on the level of adhesion between weakly alkaline basalt and asphalt, and the 3D morphology of the particles has a relatively low correlation with the level of adhesion between alkaline limestone and asphalt. The test results show that the adhesion type between asphalt and aggregate includes chemical adsorption and physical adsorption at the contact surface, and the adhesion strength is primarily determined by the bonding properties.

Acidic granite aggregates and asphalt cannot form chemical bonds on the contact surface, and physical adsorption occurs during adhesion. Therefore, the bonding strength is closely related to the $3 \mathrm{D}$ morphological characteristics of the aggregate particles. Under the experimental conditions of this research, the spalling rate of asphalt on the aggregate surface is relatively low when the $S F$ of the granite aggregate is in the range of $0.80 \leq S F \leq 0.90$ and $1.10 \leq S F \leq 1.20$, the $E$ is in the range of $0.79 \leq E \leq 0.88$, and the $J R C^{3 \mathrm{D}} \geq 14.0$. The results indicate that the rate of physical adsorption between the granite aggregate and asphalt with a compact shape, few edges and corners, and high roughness is relatively good; in addition, the probability of asphalt film damage on the aggregate surface with low roughness is high, and severe spall is more likely to occur in a water environment. Therefore, the level of adhesion between asphalt and granite aggregates is highly correlated with the $J R C^{3 \mathrm{D}}$ and has a certain correlation with the $E$.

Under the same test conditions, the spalling rate of the asphalt film on the basalt aggregate surface was low, and damage occurred mainly at the edges and corners. The experimental results show that chemical bond adsorption exists between the basalt aggregate and bitumen at the contact interface. However, due to significant changes in the curvature at the edges and corners, mechanical adhesion of the asphalt decreased; therefore, the damage and peeling of the asphalt film mainly occurred at the edges and corners in the water boiling test, and the correlation between the angularity of the basalt aggregate and the stripping rate was higher than that between the roughness and the stripping rate.

The chemical bond between the limestone aggregate and the asphalt was not easily broken in a water environment. Therefore, the adhesion between the two road materials was due to chemical adsorption, and the physical adsorption rate was relatively small. The correlation between the $J R C^{3 \mathrm{D}}$ and the adhesion level was low. 

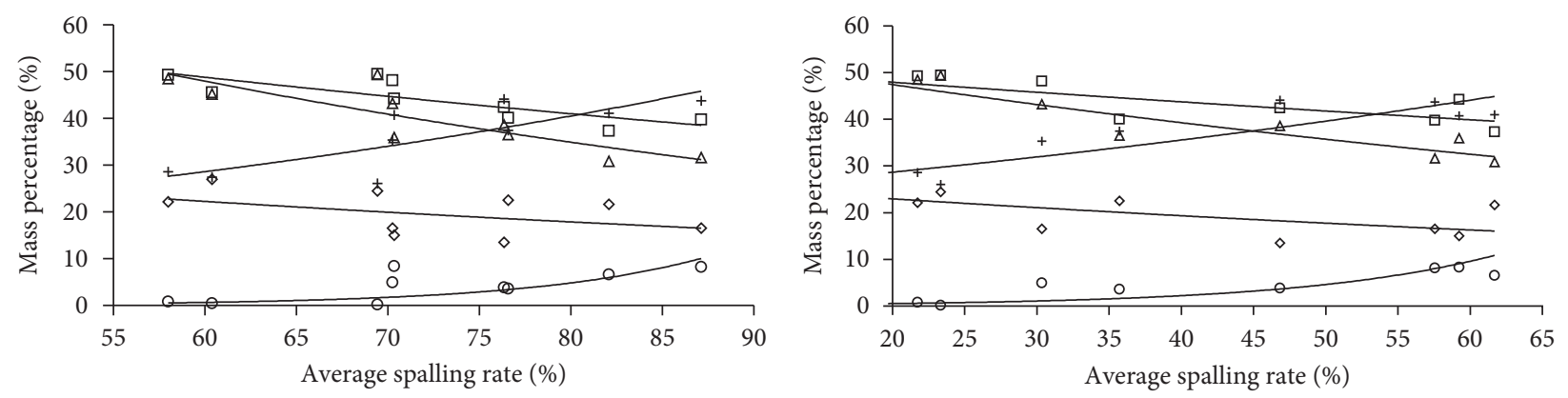

$$
\begin{aligned}
& \diamond \begin{array}{l}
\mathrm{S} \\
R^{2}=0.19
\end{array} \\
& +\begin{array}{l}
\mathrm{Ar} \\
R^{2}=0.63
\end{array} \\
& \Delta \begin{array}{l}
\mathrm{R} \\
R^{2}=0.74
\end{array}
\end{aligned}
$$$$
\text { ○ } \begin{aligned}
& \text { As } \\
& R^{2}=0.4
\end{aligned}
$$$$
\text { R }+ \text { As }
$$
$\diamond \stackrel{\mathrm{S}}{R^{2}=0.37}$
$\circ \begin{aligned} & \text { As } \\ & R^{2}=0.65\end{aligned}$
$+\begin{aligned} & \mathrm{Ar} \\ & R^{2}=0.79\end{aligned}$
$\mathrm{R}+\mathrm{As}$
$R^{2}=0.60$

$\mathrm{R}$
$R^{2}=0.79$

(a)

(b)

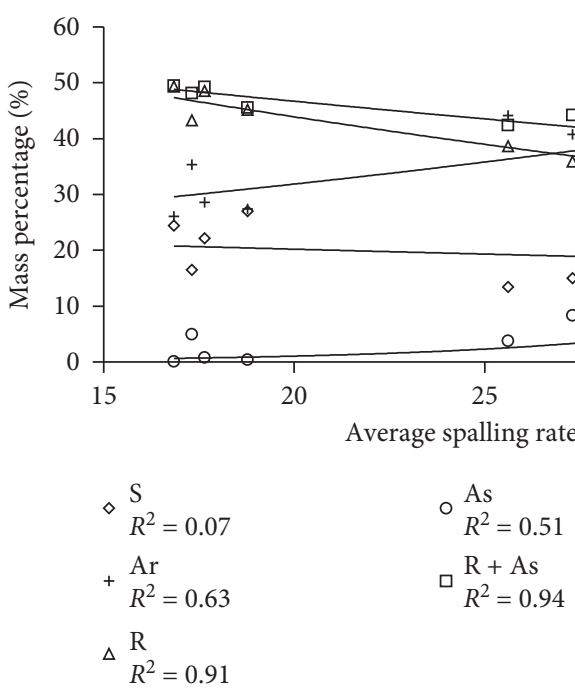

(c)

FIGURE 12: Effect of asphalt composition on the adhesion level between the aggregate and asphalt: (a) granite; (b) basalt; (c) limestone.

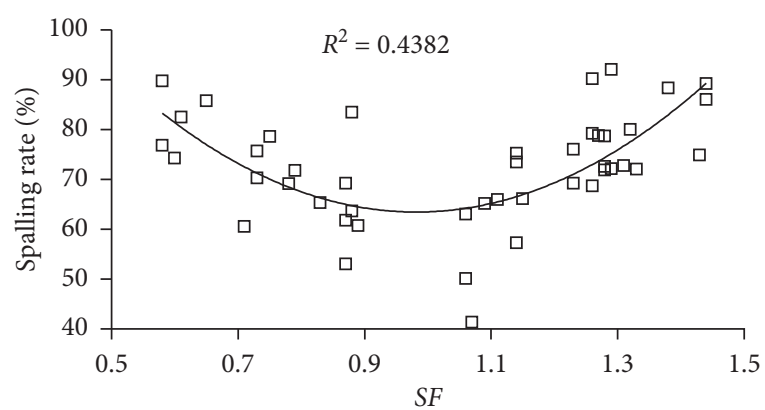

(a)

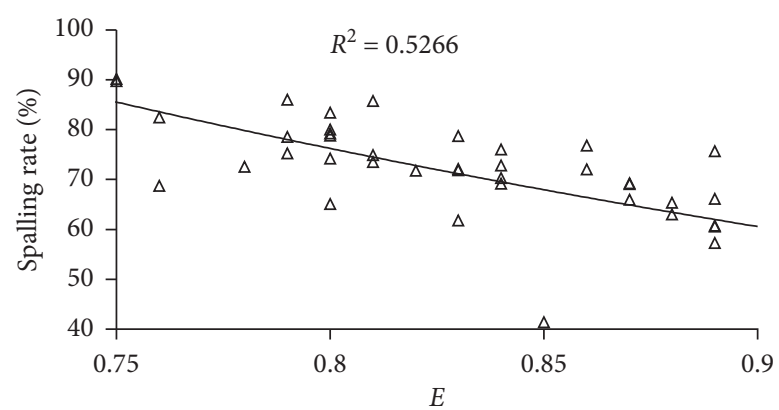

(b)

Figure 13: Continued. 


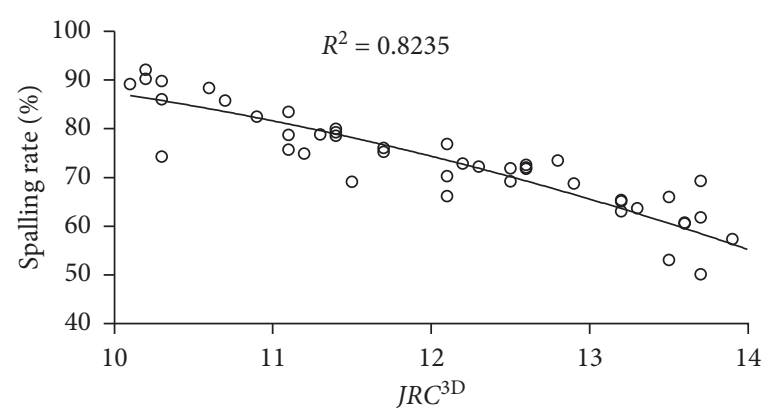

(c)

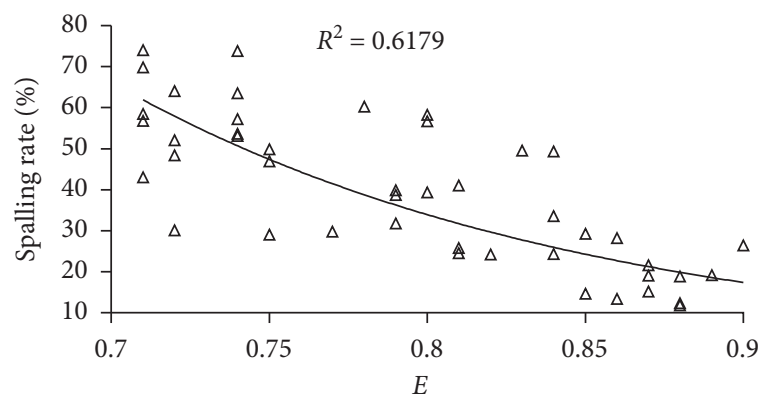

(e)

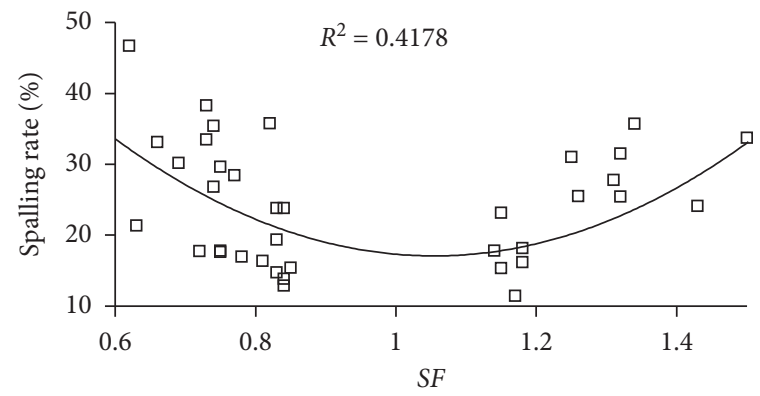

(g)

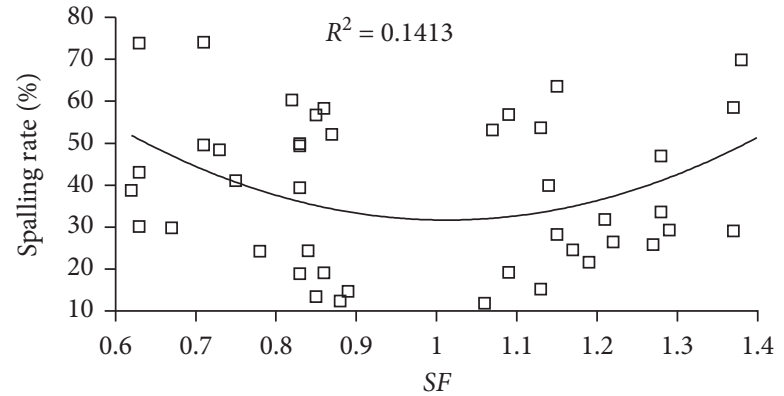

(d)

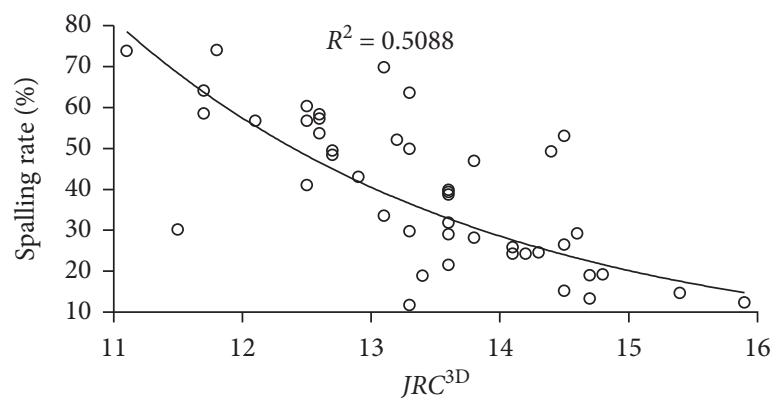

(f)

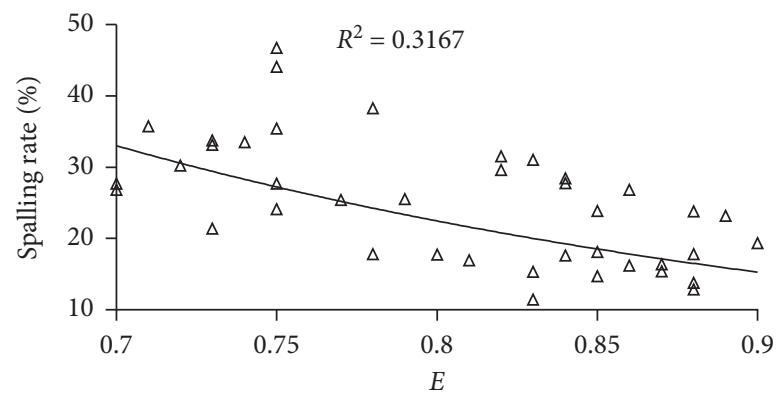

(h)

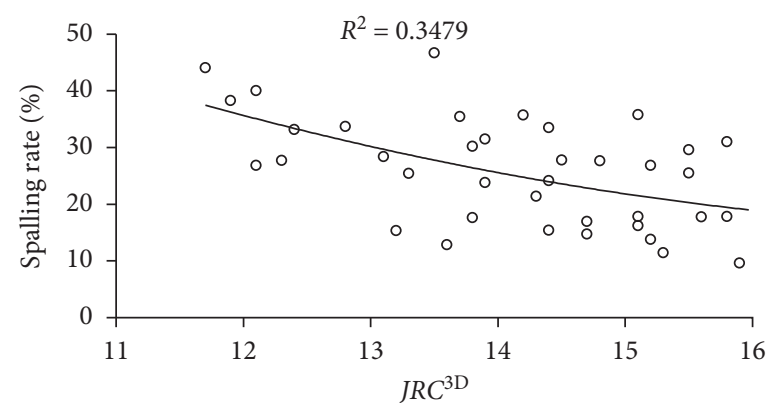

(i)

Figure 13: Influence of 3D morphology of the aggregate on adhesion of the aggregate and asphalt. (a) Correlation between the shape characteristics and the spalling rate of the granite aggregates. (b) Correlation between the angularity characteristics and the spalling rate of the granite aggregate. (c) Correlation between the roughness characteristics and the spalling rate of the granite aggregate. (d). Correlation between the shape characteristics and the spalling rate of the basalt aggregate.(e) Correlation between the angularity characteristics and the spalling rate of the basalt aggregate.(f) Correlation between the roughness characteristics and the spalling rate of the basalt aggregate. (g) Correlation between the shape characteristics and the spalling rate of the limestone aggregate. (h) Correlation between the angularity characteristics and the spalling rate of the limestone aggregate.(i) Correlation between the roughness characteristics and the spalling rate of the limestone aggregate. 


\section{Conclusions}

In this study, we proposed a quantitative method to evaluate the $3 \mathrm{D}$ morphology of aggregate surface to investigate the influence of the chemical composition of asphalt and the 3D morphology of the aggregate on contact surface adhesion. The following results were obtained:

(1) The $S$ can describe the compactness of the aggregate shape, the $S F$ can describe the needle-flake properties of the aggregate, the $E$ can evaluate the sharp edges and corners of the aggregate, the maximum surface curvature can be used to identify the local angular features of the particles, the $J R C^{2 \mathrm{D}}$ can be used to analyze the anisotropic characteristics of the surface profile of aggregate, and the $J R C^{3 \mathrm{D}}$ is suitable for evaluating the roughness of the aggregate surface texture at the mesoscopic level.

(2) The adhesion between the aggregates and asphalt on the contact surface includes chemical adsorption and physical adsorption. Chemical adsorption is relatively strong, and desorption does not occur readily, whereas physical adsorption is relatively weak, and desorption occurs readily. The strength of physical adsorption is determined by the charge properties on the surface of the raw material and the $3 \mathrm{D}$ morphological characteristics of the aggregate particles.

(3) For good adhesion between asphalt and aggregate, alkaline limestone aggregate should be used with asphalt with high resin and asphaltene contents. Weakly alkaline basalt aggregate should be used with asphalt with high resin content, and the use of highly angular mineral aggregates should be avoided. Acid aggregates should have a compact shape, relatively few edges, and a rough surface, and the physical adsorption between the aggregate and asphalt can be enhanced by improving the mechanical adhesion between the aggregate and asphalt on the contact surface.

(4) Under the experimental conditions of this study, the level of adhesion between the aggregate and asphalt is relatively high when the $S F$ of the granite aggregate is in the range of $0.80 \leq S F \leq 0.90$ and $1.10 \leq S F \leq 1.20$, the $E$ is in the range of $0.79 \leq E \leq 0.88$, and the JRC3D $\geq 14.0$.

\section{Data Availability}

The data used to support the findings of this study are available from the first author upon request.

\section{Conflicts of Interest}

The authors declare that they have no conflicts of interest.

\section{Acknowledgments}

The research was funded by the National Natural Science Fund (51708267).

\section{References}

[1] P. Redelius and N. Kringos, "Using stripping work between asphalt-aggregate system," Construction and Building Materials, vol. 176, pp. 422-431, 2018.

[2] M. Guo, A. Bhasin, and Y. Tan, "Effect of mineral fillers adsorption on rheological and chemical properties of asphalt binder," Construction and Building Materials, vol. 141, pp. 152-159, 2017.

[3] J. Yi, X. Pang, D. Feng et al., "Studies on surface energy of asphalt and aggregate at different scales and bonding property of asphalt-aggregate system," Road Materials and Pavement Design, vol. 19, no. 5, pp. 1102-1125, 2017.

[4] R. Moraes, R. Velasquez, and H. Bahia, "Using bond strength and surface energy to estimate moisture resistance of asphaltaggregate systems," Construction and Building Materials, vol. 130, pp. 156-170, 2017.

[5] A. R. Azarhoosh, F. Moghadas Nejad, and A. Khodaii, "The influence of cohesion and adhesion parameters on the fatigue life of hot mix asphalt," The Journal of Adhesion, vol. 93, no. 13, pp. 1048-1067, 2016.

[6] A. Khan, P. Redelius, and N. Kringos, "Evaluation of adhesive properties of mineral-bitumen interfaces in cold asphalt mixtures," Construction and Building Materials, vol. 125, pp. 1005-1021, 2016.

[7] A. Bhasin and D. N. Little, "Application of microcalorimeter to characterize adhesion between asphalt binders and aggregates," Journal of Materials in Civil Engineering, vol. 21, no. 6, pp. 235-243, 2009.

[8] X. Yu, N. A. Burnham, R. B. Mallick, and M. Tao, "A systematic AFM-based method to measure adhesion differences between micron-sized domains in asphalt binders," Fuel, vol. 113, no. 5, pp. 443-447, 2013.

[9] M. Guo and Y. Tan, "Interaction between asphalt and mineral fillers and its correlation to mastics' viscoelasticity," International Journal of Pavement Engineering, vol. 1, 2019.

[10] M. Guo, H. Liu, Y. Jiao et al., "Effect of WMA-RAP technology on pavement performance of asphalt mixture: a state-of-theart review," Journal of Cleaner Production, vol. 266, Article ID 121704, 2020.

[11] T. Ishibashi, Y. Fang, D. Elsworth et al., "Hydromechanical properties of $3 \mathrm{D}$ printed fractures with controlled surface roughness: insights into shear-permeability coupling processes," International Journal of Rock Mechanics and Mining Sciences, vol. 128, Article ID 104271, 2020.

[12] P. Jerónimo, R. Resende, and E. Fortunato, "An assessment of contact and laser-based scanning of rock particles for railway ballast," Transportation Geotechnics, vol. 22, Article ID 100302, 2020.

[13] Z. Q. Xiong, Q. Jiang, Y. H. Gong et al., "Modeling natural joint of rock mass using three dimensional scanning and printing technologies and printing technologies and its experimental verification," Rock and Soil Mechanics, vol. 36, no. 6, pp. 1566-1572, 2015.

[14] N. Babanouri, M. Asadizadeh, and Z. H. Alizade, "Modeling shear behavior of rock joints: a focus on interaction of influencing parameters," International Journal of Rock Mechanics and Mining Sciences, vol. 22, Article ID 104449, 2020.

[15] K. G. Larkin, "Efficient nonlinear algorithm for envelope detection in white light interferometry," Journal of the Optical Society of America A, vol. 13, no. 4, pp. 832-843, 1996.

[16] A. Hirabayashi, H. Ogawa, and K. Kitagawa, "Fast surface profiler by white-light interferometry by use of a new 
algorithm based on sampling theory," Applied Optics, vol. 41, no. 23, pp. 4876-4883, 2002.

[17] Z. R. Tang, M. Z. Liu, Y. Jiang et al., "Point cloud registration algorithm based on canonical correlation analysis," Chinese Journal of Lasers, vol. 46, no. 4, pp. 173-181, 2019.

[18] X. Cui, X. T. Yan, and S. P. Li, "Feature-preserving scattered point cloud denoising," Opticsand Precision Engineering, vol. 25, no. 12, pp. 3169-3178, 2017.

[19] X. Wu, L. X. Lu, D. D. Liang et al., "Comparison of surface reconstruction algorithms based on point cloud data," Journal of Anhui Normal University(Natural Science), vol. 42, no. 1, pp. 46-50, 2019.

[20] L. Z. Wu, H. W. Gao, and F. W. Meng, "NURBS surface reconstruction and point cloud-surface error analysis," Laser \& Infrared, vol. 40, no. 10, pp. 1131-1135, 2010.

[21] Z. Cui and H. R. Duan, "Computational method of 3D aggregate angularity based on CT images," Journal of Traffic and Transportation Engineering, vol. 17, no. 5, pp. 39-49, 2017.

[22] C. Jin, P. S. Wang, X. Yang et al., "Analysis on gradation parameters of asphalt mixture based on $3 \mathrm{D}$ virtual measurement," Journal of Highway and Transportation Research and Development, vol. 36, no. 8, pp. 1-8, 2019.

[23] C. Geng, "Quantitative evaluation of morphological feature of aggregate based on image processing," Journal of Highway and Transportation Research and Development, vol. 35, no. 12, pp. 42-47, 2018.

[24] Y.-H. Lee, J. R. Carr, D. J. Barr, and C. J. Haas, "The fractal dimension as a measure of the roughness of rock discontinuity profiles," International Journal of Rock Mechanics and Mining Sciences \& Geomechanics Abstracts, vol. 27, no. 6, pp. 453-464, 1990.

[25] J. Zhao, "Joint surface matching and shear strength part B: JRC-JMC shear strength criterion," International Journal of Rock Mechanics and Mining Sciences, vol. 34, no. 2, pp. 179-185, 1997.

[26] N. Barton and V. Choubey, "The shear strength of rock joints in theory and practice," Rock Mechanics, vol. 10, no. 1-2, pp. 1-54, 1977.

[27] R. Tse and D. M. Cruden, "Estimating joint roughness coefficients," International Journal of Rock Mechanics and Mining Sciences \& Geomechanics Abstracts, vol. 16, no. 5, pp. 303-307, 1979.

[28] S. J. Chen, W. C. Zhu, C. Y. Wang et al., "Review of research progresses of the quantifying joint roughness coefficients," Chinese Journal of Theoretical and Applied Mechanics, vol. 49, no. 2, pp. 239-256, 2017.

[29] T. Belem, F. Homand-Etienne, and M. Souley, "Quantitative parameters for rock joint surface roughness," Rock Mechanics and Rock Engineering, vol. 33, no. 4, pp. 217-242, 2000.

[30] M. C. Powers, "A new roundness scale for sedimentary particles," Journal of Sedimentary Research, vol. 23, no. 2, pp. 117-119, 1953. 